\title{
A Second-Order Standard Addition Method based on the Data Treatment by Calculation of Variation Matrix of Kinetic Systems Analyzed by MCR-ALS
}

\author{
Abdolhossein Naseri, ${ }^{* a}$ Morteza Bahram ${ }^{b}$ and Mehdi Mabhooti ${ }^{b}$ \\ ${ }^{a}$ Department of Analytical Chemistry, Faculty of Chemistry, University of Tabriz, Tabriz, Iran \\ ${ }^{b}$ Department of Chemistry, Faculty of Science, Urmia University, Urmia 57159-165, Iran
}

\begin{abstract}
Um método novo é proposto para resolver dados de cinética-espectrométrica de misturas do tipo multicomponentes e para a determinação de analito(s) na presença de matriz desconhecida. $\mathrm{O}$ método utiliza dados de matrizes de variação pelo deslocamento de alvo, denominado espaço de reação. A matriz de variação é obtida pela subtração do espectro do ponto-zero (isto é, primeiro espectro) de cada espectro a cada tempo. Este deslocamento espacial diminui os números de classificação para os números de reações. A resolução da curva de auto-modelagem é usada para resolver as matrizes dos dados de cinética-espectrométrica por matrizes de analitos. Além do mais, o método de adição padrão de segunda ordem é usado para remover o efeito(s) das matrizes para quando se analisa amostras desconhecidas. Isto significa que, a análise quantitativa pode ser realizada pela argumentação da matriz de variação das amostras desconhecidas e amostras adicionadas de padrão e, em seguida, traçar a curva de calibração de adição de padrão. A aplicabilidade do método proposto é avaliada usando dados modelo e real de misturas de analitos.
\end{abstract}

A new method is proposed to resolve the kinetic-spectrophotometric data of multicomponent mixtures and determination of analyte(s) in the presence of unknown matrix. The method uses variation matrix data by shifting to another target, namely the reaction space. The variation matrix is obtained by subtracting the zero-point spectrum (e.g., first spectrum) from each spectrum at each time. This space shifting decreases the rank numbers to the numbers of reactions. Self-modeling curve resolution is used to resolve the variation matrices of kinetic-spectrophotometric data for mixtures of analytes. In addition, second-order standard addition method is used to remove the matrix effect(s) when analyze unknown samples. This means that, quantitative analysis can be performed by augmentation of the variation matrix of the unknown samples and standard added samples and, then, plotting standard addition calibration curve. The applicability of the proposed method is evaluated using model and real data for mixtures of analytes.

Keywords: standard addition, MCR-ALS, variation matrix, kinetic data

\section{Introduction}

One of the goals of the chemometrics methods is the quantitative analysis of multicomponent systems with overlapping spectrum. Multivariate calibration methods are the branch of the chemometrics used for this purpose. These methods can be classified into first-order, second-order and higher order methods. ${ }^{1,2}$ First-order calibrations are used for first-order data. In first-order multivariate calibration (e.g. PCR and PLS), the nature and the chemical matrix of the standard samples have to be similar to those of the unknown samples. ${ }^{1,2}$ This means that the standards, which

*e-mail: a_naseri@tabrizu.ac.ir are subjected to construct a calibration model to analyze real sample(s), are real samples themselves, with nearly the same mixtures, that should be previously analyzed by an independent method. ${ }^{3}$ In second-order calibration methods, pure analyte standards are frequently used to quantify unknown samples, even in the presence of unknown and uncalibrated interferences. ${ }^{1,2}$ This is a clear advantage of the second-order calibration methods. ${ }^{4,5}$ The second-order data corresponding to kinetics data can be used for quantitative analysis. ${ }^{6,7}$ In contrast to first-order multivariate calibration, these methods simultaneously take into account the spectroscopic and the kinetic behaviors of the substances, giving as result higher selectivity and sensitivity. With the availability of rapid scanning and 
diode-array spectrometers, the second-order data are readily available, forming the basis of many chemical investigations. Moreover, the second-order algorithms avoid the need of using a large number of calibration sample since a single calibration sample, that contains the analyte of interest, is sufficient. ${ }^{8}$

Suitable algorithms for analyzing second-order data are parallel factor analysis (PARAFAC), ${ }^{9}$ the generalized rank annihilation method (GRAM) ${ }^{10}$ rank annihilation factor analysis (RAFA), ${ }^{11,12}$ direct trilinear decomposition (DTLD), ${ }^{13}$ bilinear least squares (BLLS), ${ }^{14}$ alternating trilinear decomposition (ATLD) ${ }^{15}$ and its variants (self-weighted alternating trilinear decomposition (SWATLD) ${ }^{16}$ alternating penalty trilinear decomposition $(\mathrm{APTLD}){ }^{17}$ and multivariate curve resolution-alternating least squares (MCR-ALS). ${ }^{18}$

It was shown that MCR-ALS is a powerful tool for the species resolution and the quantitative determination of many types of unresolved chemical mixtures especially in kinetic systems. ${ }^{19,20}$ Initial estimation of the concentration or spectral profiles is the first step in MCR-ALS. If the initial estimation is close to real values, the results are easily converged. On the other hand, selection and implementation of suitable constraints are another important factors that can be easily made not only to rapid convergency of the results but also to decrease the ambiguity of the solutions. Several constraints such as non-negativity, unimodality and closure are used for these purposes.

The rank deficiency is one of the main problems in analyzing of complex chemical systems using MCR-ALS. A data matrix is rank-deficient when the number of significant contributions to the data variance, that are estimated using singular value decomposition or other related factor analysis techniques, is lower than the real number of chemical components present in the system. ${ }^{21}$ Such situation occurs quite frequently when, for instance, at the beginning of a chemical reaction or process, more than one component already exists or parallel reactions take place. ${ }^{21,8}$ This problem will also occur when the reaction of one of the component immediately takes place and produces a constant signal during the time range of the experiments. ${ }^{21}$

Variation matrix is one of the concepts proposed for handling the rank deficiency problem in parallel reaction systems. ${ }^{22,23}$ In this approach, variation matrix (difference spectra) is used instead of the original data matrix, which is obtained by subtracting the zero-point spectrum from each spectrum at each measurement point. ${ }^{24-26}$ Variation matrix can be decomposed to reaction extent vectors and reaction spectra. Reaction extent vector designates the net variation in concentration between the $\mathrm{i}^{\text {th }}$ point and a specified zero-point. ${ }^{22,23}$
One of the aims of the present study was to develop a theoretical formula for estimation and description of the rank of a system with parallel reactions based on the reaction rank instead of the chemical rank. The rank of a matrix based on a number of independent reactions is called the reaction rank. For example, extent profiles and related reaction spectra can be extracted instead of concentration profiles and pure spectra. ${ }^{22,23,26}$ Representation of a system based on its reaction rank is very useful because it is possible to convert a chemical rank-deficient system to full-rank reaction system by simple pretreatment.

In our previous work, the coupling of the variation matrix and MCR-ALS was successfully applied to resolve $\mathrm{pH}$-spectrophotometric data to determine some food colorants with acid-base behaviors. ${ }^{26}$ In this study, it was shown that the reaction extent vector linearly depended on the initial concentration of the reactant. Thus, in the kinetic system containing different reactions, the variation matrix can be decomposed by the self-modeling curve resolution method such as MCR-ALS.

On the other hand, the possible change in the sensitivity of the analyte response as a result of the matrix effect cannot be modeled with second-order calibration models since pure standards do not provide information about the chemical matrix of the sample. Therefore, if the sensitivity of the calibration depends on the chemical composition of the matrix, predictions may be poorer when calibration curves are obtained from pure standards. ${ }^{27}$ Many studies have been based on the second-order techniques but few of them have considered the matrix effects in complex samples or provided solutions for solving them. ${ }^{28}$ Coupling of standard addition method and MCR-ALS have been used to solve the matrix effect problem in second-order data. ${ }^{27-30}$

In this work, standard addition data corresponding to variation matrix were analyzed by MCR-ALS in order to combine their advantages. Simultaneous analysis of four variation matrices using MCR-ALS was performed on an augmented matrix that is related to variation matrix of unknown sample and those of standard addition matrices. This was arranged by setting unknown variation matrix on top of the other in order to keep the common spectra in the same column.

In this work, several data are simulated and the corresponding variation matrices are analyzed by MCR-ALS. Finally, a complexation reaction of $\mathrm{Ni}(\mathrm{II})$ and $\mathrm{Co}(\mathrm{II})$ with chromogenic reagent 1-(2-pyridylazo) 2-naphthol (PAN) as a real experimental study is presented. In addition, a multicomponent determination of these ions in various alloy samples was studied by the proposed method. A case interferent $\mathrm{Cu}(\mathrm{II})$, that immediately reacts with PAN and produces a constant signal during the experimental time, 
is added to synthetic samples in order to study the effect of unknown interferent(s) and/or presence of a constant signal.

To the best of our knowledge this is the first study for analyzing of kinetic-spectrophotometric data (e.g. complexometric data recording versus time) by combination of variation matrix and multivariate curve resolution.

\section{Experimental}

\section{Apparatus}

A PerkinElmer Lambda 45 fast-scan UV-Visible spectrometer was used for recording of UV-Visible absorbance spectra using $10 \mathrm{~mm}$ quartz cells. A Metrohm model 713 pH-meter with a combined glass electrode was used for $\mathrm{pH}$ measurements. All calculations in the computing process were performed in Matlab and Microsoft Excel for Windows.

\section{Reagents}

All chemicals were of analytical reagent grade and triple distilled water was used throughout the experiments. Stock $\mathrm{Co}(\mathrm{II}), \mathrm{Cu}(\mathrm{II})$ and $\mathrm{Ni}(\mathrm{II})$ solutions (1000 $\mathrm{mg} \mathrm{L}^{-1}$ ) were prepared by dissolving appropriate amounts of $\mathrm{Co}\left(\mathrm{NO}_{3}\right)_{6} \cdot 6 \mathrm{H}_{2} \mathrm{O}, \mathrm{CuSO}_{4} \cdot 6 \mathrm{H}_{2} \mathrm{O}$ and $\mathrm{NiSO}_{4} \cdot 6 \mathrm{H}_{2} \mathrm{O}$ in water. $\mathrm{A}$ $5.0 \times 10^{-3} \mathrm{~mol} \mathrm{~L}^{-1} \mathrm{PAN}$ solution was prepared by dissolving $128 \mathrm{mg}$ of PAN in $100 \mathrm{~mL}$ hot ethanol. Citrate buffer solution (1 mol L ${ }^{-1}$ ) of $\mathrm{pH} 5.8$ was prepared from sodium citrate salt and sulfuric acid. Triton X-100 stock solution (14\%, v/v) was prepared by dissolving $14 \mathrm{~mL}$ of concentrate solution (Merck, Darmstadt, Germany) in hot distilled water.

\section{Procedure}

All the solutions were equilibrated at $25 \pm 0.1^{\circ} \mathrm{C}$ before the beginning of the reactions. An aliquot of the solution containing 1-20 $\mu \mathrm{g}$ of $\mathrm{Co}(\mathrm{II}), \mathrm{Cu}(\mathrm{II})$ and $\mathrm{Ni}(\mathrm{II})$ cations was transferred into $10 \mathrm{~mL}$ volumetric flask containing $1 \mathrm{~mL}$ of $\mathrm{pH} 5.8$ citrate buffer solution. Then, $1 \mathrm{~mL}$ of $14 \%$ Triton X-100 and $2 \mathrm{~mL}$ of $5.0 \times 10^{-3} \mathrm{~mol} \mathrm{~L}^{-1}$ PAN solutions were added. After diluting the solution to the mark with triply distilled water, a portion of it was immediately transferred into a quartz cell and 20 absorbance spectra (0-10 min) were recorded at 76 wavelength channels in the range of 550-700 $\mathrm{nm}$.

\section{Theory and algorithm}

\section{Theory}

Consider a closed system in which kinetic complexation reactions for a mixture of three metal ions (M, N and $\mathrm{P}$ ) are taking place. The involved independent reactions are as follows:
$\mathrm{M}+\mathrm{L} \rightarrow \mathrm{ML}$
$\mathrm{N}+\mathrm{L} \rightarrow \mathrm{NL}$
$\mathrm{P}+\mathrm{L} \rightarrow \mathrm{PL}$

The extent of the reaction describes the progress of a chemical reaction, that is equal to the number of chemical transformations, defined as equation $2::^{22-24}$

$$
\begin{aligned}
& \boldsymbol{\varepsilon}_{\mathrm{M}}=-\Delta \mathbf{c}_{\mathrm{M}}=\Delta \mathbf{c}_{\mathrm{ML}} \\
& \boldsymbol{\varepsilon}_{\mathrm{N}}=-\Delta \mathbf{c}_{\mathrm{N}}=\Delta \mathbf{c}_{\mathrm{NL}} \\
& \boldsymbol{\varepsilon}_{\mathrm{P}}=-\Delta \mathbf{c}_{\mathrm{P}}=\Delta \mathbf{c}_{\mathrm{PL}}
\end{aligned}
$$

where $\Delta \mathbf{c}_{\mathrm{j}}$ is the concentration variation vector whose elements represent the variation of component $j$ between a given moment and a specified zero-point. $\varepsilon$ is the extent of the reaction vector whose elements designate the reaction extent at these points. The reaction extent, a basic physical concept, describes the progress of a chemical reaction. Then:

$\mathbf{c}_{\mathrm{j}}=\lambda \varepsilon_{r}+1 \mathbf{c}_{\mathrm{j}}^{0}$

where 1 is a vector with all elements being 1 and $\lambda$ is the stoichiometry coefficient for component $j$ ( $\lambda$ is -1 for the reactant and +1 for the product in this example). $\mathbf{c}_{\mathrm{j}}^{0}$ is the concentration of component $j$ at the zero-point and $\mathbf{c}_{\mathbf{j}}$ is the concentration vector for component $j$.

In the above mentioned example, concentrations of ML and $\mathrm{M}$ can be calculated using the following extent vector:

$\mathbf{c}_{\mathrm{ML}}=\boldsymbol{\varepsilon}_{\mathrm{M}}+\mathbf{1} \mathbf{c}_{\mathrm{ML}}^{0} \quad$ (a)
$\mathbf{c}_{\mathrm{M}}=-\boldsymbol{\varepsilon}_{\mathrm{M}}+\mathbf{1} \mathbf{c}_{\mathrm{M}}^{0} \quad$ (b)

Concentration vectors of other components $\left(\mathbf{c}_{\mathrm{NL}}, \mathbf{c}_{\mathrm{N}}\right.$, $\mathbf{c}_{\mathrm{PL}}$ and $\mathbf{c}_{\mathrm{N}}$ ) can be calculated as described for ML and $\mathrm{M}$. The concentration of ligand (L), which associates in all the three reactions, can be stated as equation 5 :

$\mathbf{c}_{\mathrm{L}}=\mathbf{1} \mathbf{c}_{\mathrm{L}}^{0}-\boldsymbol{\varepsilon}_{\mathrm{M}}-\boldsymbol{\varepsilon}_{\mathrm{N}}-\boldsymbol{\varepsilon}_{\mathrm{P}}$

According to the Beer-Lambert law, the contributed absorbance by reaction system can be expressed as equation 6 :

$$
\mathbf{D}=\mathbf{C S}=\mathbf{c}_{\mathrm{ML}} \mathbf{s}_{\mathrm{ML}}{ }^{\mathrm{T}}+\mathbf{c}_{\mathrm{NL}} \mathbf{s}_{\mathrm{NL}}^{\mathrm{T}}+\mathbf{c}_{\mathrm{PL}} \mathbf{s}_{\mathrm{PL}}^{\mathrm{T}}+\mathbf{c}_{\mathrm{L}} \mathbf{s}_{\mathrm{L}}^{\mathrm{T}}
$$

where $\mathbf{s}_{\mathrm{ML}}, \mathbf{s}_{\mathrm{NL}}$ and $\mathbf{s}_{\mathrm{PL}}$ represent the spectra of the complexed forms of $\mathrm{M}, \mathrm{N}$ and $\mathrm{P}$, respectively (i.e., ML, NL and PL). 
Because the concentrations of modeled and/or experimental metallic cations are very low, it was assumed that these cations themselves are inactive in the working wavelength range. It should be also stated that this methodology is always carried out using an excess amount of ligand with respect to the total concentration of metals to ensure the complete formation of the related complexes, as well, otherwise, the methodology would not have quantitative value.

The substitution of equations 4 and 5 in equation 6 gives equation 7 :

$$
\begin{aligned}
\mathbf{D}= & \left(\boldsymbol{\varepsilon}_{\mathrm{M}}+\mathbf{1} \mathbf{c}_{\mathrm{ML}}^{0}\right) \mathbf{s}_{\mathrm{ML}}{ }^{\mathrm{T}}+\left(\boldsymbol{\varepsilon}_{\mathrm{N}}+\mathbf{1} \mathbf{c}_{\mathrm{NL}}^{0}\right) \mathbf{s}_{\mathrm{NL}}{ }^{\mathrm{T}}+\left(\varepsilon_{\mathrm{P}}+\mathbf{1} \mathbf{c}_{\mathrm{PL}}^{0}\right) \mathbf{s}_{\mathrm{PL}}{ }^{\mathrm{T}} \\
& +\left(\mathbf{1} \mathbf{c}_{\mathrm{L}}^{0}-\varepsilon_{\mathrm{M}}-\varepsilon_{\mathrm{N}}-\varepsilon_{\mathrm{P}}\right) \mathbf{s}_{\mathrm{L}}^{\mathrm{T}} \\
= & \varepsilon_{\mathrm{M}}\left(\mathbf{s}_{\mathrm{ML}}-\mathbf{s}_{\mathrm{L}}\right)^{\mathrm{T}}+\varepsilon_{\mathrm{N}}\left(\mathbf{s}_{\mathrm{NL}}-\mathbf{s}_{\mathrm{L}}\right)^{\mathrm{T}}+\varepsilon_{\mathrm{P}}\left(\mathbf{s}_{\mathrm{PL}}-\mathbf{s}_{\mathrm{L}}\right)^{\mathrm{T}}+ \\
& \left(\mathbf{1} \mathbf{c}_{\mathrm{ML}}^{0} \mathbf{s}_{\mathrm{ML}}{ }^{\mathrm{T}}+\mathbf{1} \mathbf{c}_{\mathrm{NL}}^{0} \mathbf{s}_{\mathrm{NL}}{ }^{\mathrm{T}}+\mathbf{1} \mathbf{c}_{\mathrm{PL}}^{0} \mathbf{s}_{\mathrm{PL}}{ }^{\mathrm{T}}+\mathbf{1} \mathbf{c}_{\mathrm{L}}^{0} \mathbf{s}_{\mathrm{L}}^{\mathrm{T}}\right) \\
= & \varepsilon_{\mathrm{M}}\left(\mathbf{s}_{\mathrm{ML}}-\mathbf{s}_{\mathrm{L}}\right)^{\mathrm{T}}+\varepsilon_{\mathrm{N}}\left(\mathbf{s}_{\mathrm{NL}}-\mathbf{s}_{\mathrm{L}}\right)^{\mathrm{T}}+\varepsilon_{\mathrm{P}}\left(\mathbf{s}_{\mathrm{PL}}-\mathbf{s}_{\mathrm{L}}\right)^{\mathrm{T}}+\mathbf{1} \mathbf{s}^{0^{\mathrm{T}}}
\end{aligned}
$$

where $\left(\mathbf{s}_{\mathrm{ML}}-\mathbf{s}_{\mathrm{L}}\right),\left(\mathbf{s}_{\mathrm{NL}}-\mathbf{s}_{\mathrm{L}}\right)$ and $\left(\mathbf{s}_{\mathrm{PL}}-\mathbf{s}_{\mathrm{L}}\right)$ are three reaction spectra and $\mathbf{s}^{0}$ is zero-point spectrum (first row of data matrix). All of them are linear combinations of the pure spectra of the components. The zero-point spectrum is the linear combination of the pure component spectra weighted by the initial concentration of the components and the reaction spectrum is the linear combination of the pure component spectra but weighted by stoichiometric coefficients, with signs of "-“" and "+" for reactants and products, respectively. Thus, the absorbance matrix $\mathbf{D}$ can be expressed in matrix form as equation 8 :

$\mathbf{D}=\mathbf{E} \mathbf{S}^{\mathrm{r}^{\mathrm{T}}}+\mathbf{1} \mathbf{s}^{0^{\mathrm{T}}}=\mathbf{V}+\mathbf{1} \mathbf{s}^{0^{\mathrm{T}}}$,

where $\mathbf{E}$ and $\mathbf{S}^{\mathrm{r}}$ are the reaction extent matrix and reaction spectra matrix, respectively. The columns of $\mathbf{E}$ and $\mathbf{S}^{\mathrm{r}}$ are reaction extents and reaction spectra, so their rank is equal or less than the number of independent reactions in data matrix. $\mathbf{V}$ is the variation matrix that is the product of $\mathbf{E}$ and $\mathbf{S}^{\mathrm{r}^{\mathrm{T}}}$.

Then, equation 8 can be simplified to:

$\mathbf{V}=\mathbf{D}-\mathbf{1} \mathbf{s}^{0^{\mathrm{T}}}=\mathbf{D}-\mathbf{1 D}(1 .:)$,

According to equation 9, the variation matrix can be constructed if the zero-point spectrum is subtracted from the spectrum of each measurement point.

The rank of a matrix based on a number of independent reactions is called the reaction rank. Thus, a variation matrix will be a full-rank matrix in terms of the number of analytes if each analyte is involved in a one-step reaction, as it is the case for kinetic complexation reaction.
Curve resolution methods can be applied to resolve the variation matrix $\mathbf{V}$. It can be also used to obtain the reaction extent matrix $\mathbf{E}$ and the reaction spectra matrix $\mathbf{S}^{\mathrm{r}} .22-24,31$

From equation 7, it can be concluded that, for a closed system containing $K$ independent reactions or processes (e.g., complexation reaction of a mixture of $K$ metal cations with a ligand) and given that the ligand and all complexes involved are spectrophotometrically active, the pseudo-rank of the measurement matrix $\mathbf{D}$ will be $\leq K+1$, $\mathrm{S}$ where $\mathrm{S}$ is the number of absorbing species participating in the reactions. ${ }^{21}$ Whereas the pseudo-rank of variation matrix $\mathbf{V}$ is $\leq \min (\mathbf{K}, \mathbf{S}) .^{21-23}$ If inert compound (e.g. when the reaction of one of the components immediately takes place and produces a constant signal during the experiment) exists in kinetic data, the pseudo-rank of data matrix will be less than the chemical rank. In other words, the data matrix will be rank deficient. It is possible to convert this rank deficient system to a new full reaction rank system by simple pretreatment, calculation of variation matrix. The contribution of inert unknown compounds will be removed in the step of the calculation of the variation matrix. Therefore, the presence of such compounds does not perturb the data resolution, which is one of the advantages of the proposed algorithm.

It should be noted that the elements of the reaction extent vector are non-negative and monotonically increase with time. Moreover, the reaction extent at the specified zero time is zero. These properties play critical roles in the evaluation of the resolution results and implementation of physically plausible constraints in resolution procedures. ${ }^{22}$

The obtained data are second-order. This property allows to accurate quantization of multiple analytes using a calibration sample containing multiple chemical components without knowledge of the interfering chemical components that may be present in the sample being analyzed (second-order advantage). Among different second-order algorithms, MCR-ALS was used in this work.

\section{Algorithm of the proposed method}

The algorithm of the proposed method for quantitative analysis is as follows.

(i) Calculation and column wise augmentation of the variation matrices of unknown and standard added samples.

Column wise augmented matrices are built by putting the variation of unknown sample, $\mathbf{V}_{w^{\prime}}$ on top and those of standard added samples, $\mathbf{V}_{u+s}$, on below. It should be noted that the variational matrices of unknown and standard added samples have equivalents zero-point vectors, relative to the beginning of the reaction. 


\section{(ii) Rank estimation}

Singular value decomposition can be used to estimate the rank of augmented variation matrices, $\mathrm{V}_{\text {aug }}$. As mentioned, the rank of $\mathrm{V}_{\text {aug }}$ is equal to the number of active reactions.

\section{(iii) ALS optimization}

The iterative ALS procedure starts with initial estimation of the reaction spectra $\left(\mathrm{S}^{\mathrm{r}}\right)$. A suitable initial estimation method such as SIMPLISMA can be applied to estimate the reaction spectra prior to MCR-ALS:

$\mathbf{V}_{\text {aug }}=\mathbf{E}_{\text {aug }} \mathbf{S}^{\mathbf{r}^{\mathrm{T}}}+\mathbf{R}$

where $\mathbf{R}$ is the matrix of residuals that is not explained by the chemical reactions in $\mathbf{E}$ and $\mathbf{S}^{\mathrm{r}^{\mathrm{T}}}$ and should be close to the experimental error. Depending on the nature and structure of the data, different constraints can be applied during ALS optimization. Non-negativity and unimodality of the reaction extent vectors could be used as suitable constraints in the proposed method.

(iv) Quantification step

The quantification is performed by plotting standard addition curve. In this step, the areas below the reaction extent curve of the analyte in each sample are plotted versus the standard added concentrations.

\section{Results and Discussion}

\section{Simulation}

The performance of the proposed method was evaluated using several sets of simulated data. The data set $\left(\mathbf{D}_{1}\right)$ in Figure 1 was simulated from artificially constructed UV-Vis spectra and kinetic profiles. It was formed by 91 spectra (1-10 min with increment of $0.1 \mathrm{~min}$ ) of 251 absorbance values (350-600 nm with increment of $1 \mathrm{~nm}$ ). The simulated kinetic models are three simple parallel pseudo-first order complexation reactions in which one of the reactions instantaneously takes place and two other reaction with reaction rate constants $\mathrm{k}_{1}=0.10 \mathrm{~min}^{-1}$ and $\mathrm{k}_{2}=0.40 \mathrm{~min}^{-1}$, respectively. As shown in Figure 1, it was assumed that the reaction of one of the components $(\mathrm{P})$ immediately takes place and produces a constant signal during the time range of the experiments. This component was assumed as an interferent with constant signal that could be present in unknown sample analysis. The standard added data sets were simulated at the same way as $\mathbf{D}_{1}$, but with adding different concentration of $\mathbf{M}$, as an analyte, to above mentioned data set, $\mathbf{D}_{1}$. The variation of sample data (simulated ternary mixtures in this case) and those of standard added samples were obtained by subtracting each row of the data matrix by the first row of that matrix and then, column wise augmented.
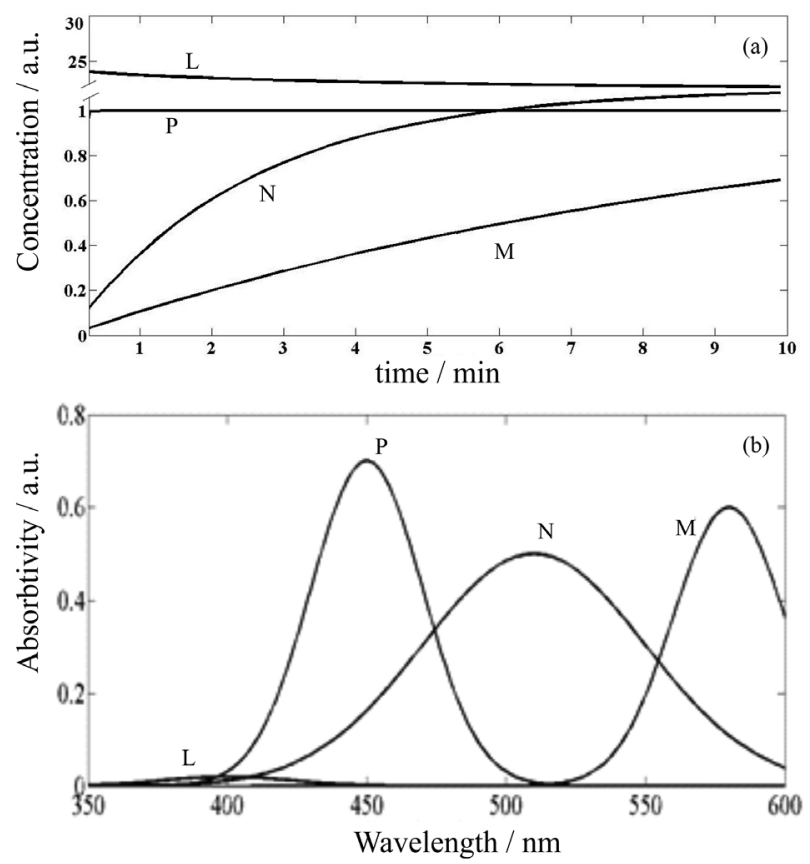

Figure 1. Simulated kinetic profiles (a) and spectra (b) for parallel complexation reaction of $\mathrm{M}, \mathrm{N}$ and $\mathrm{P}$ with $\mathrm{L}$.

Figure 2 represents the direct $\left(\mathbf{D}_{1}\right)$ and its variation $(\mathbf{V})$ for a case simulated two-way data of ternary mixture. The contribution of inert unknown compounds is removed in
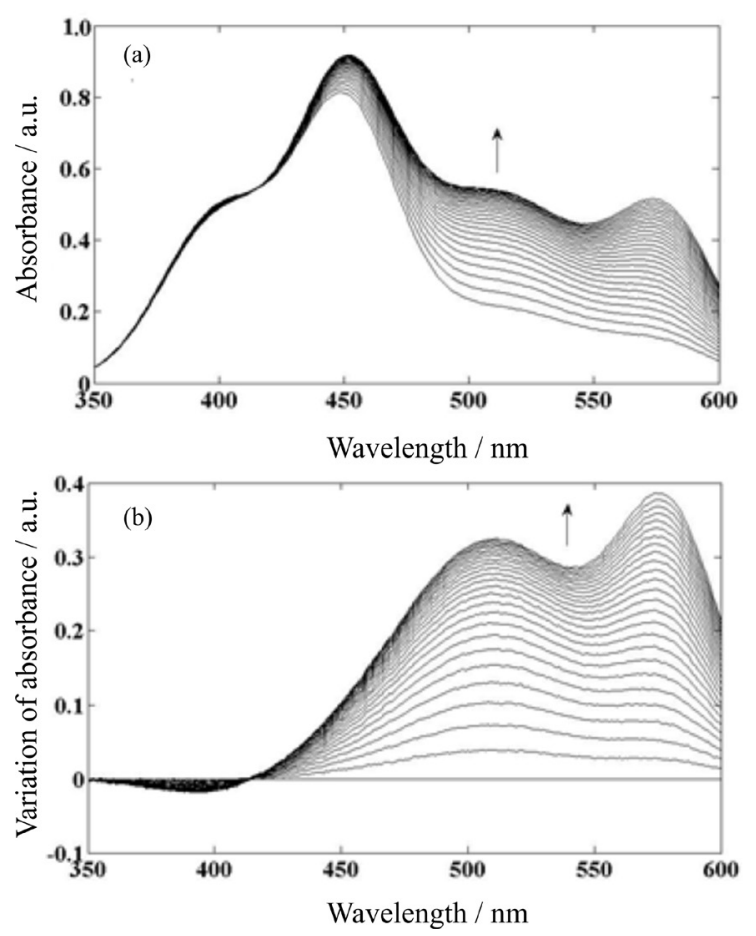

Figure 2. Simulated spectra for parallel complexation reaction of $\mathrm{M}$, $\mathrm{N}$ and $\mathrm{P}$ with $\mathrm{L}$ (a) and the variation of data (b). 
Table 1. Composition and results of analysis of modeled data of $\mathrm{M}$ and $\mathrm{N}$ mixtures in the presence different amount of $\mathrm{P}$ by proposed method

\begin{tabular}{|c|c|c|c|c|c|c|c|}
\hline \multirow{2}{*}{ Sample number } & \multicolumn{3}{|c|}{ Composition / $\left(\mu \mathrm{g} \mathrm{mL}^{-1}\right)$} & \multicolumn{2}{|c|}{ Predicted concentration / $\left(\mu \mathrm{g} \mathrm{mL}^{-1}\right)$} & \multicolumn{2}{|c|}{ Recovery / \% } \\
\hline & $\mathrm{M}$ & $\mathrm{N}$ & $\mathrm{P}$ & M & $\mathrm{N}$ & $\mathrm{M}$ & $\mathrm{N}$ \\
\hline 1 & 0.77 & 0.27 & 0.46 & 0.76 & 0.28 & 98.70 & 104.44 \\
\hline 2 & 0.21 & 1.08 & 0.54 & 0.22 & 1.11 & 104.76 & 102.77 \\
\hline 3 & 0.88 & 1.04 & 0.31 & 0.855 & 1.02 & 97.15 & 98.07 \\
\hline 4 & 0.87 & 0.44 & 0.74 & 0.88 & 0.43 & 101.14 & 97.72 \\
\hline 5 & 0.3 & 0.85 & 0.46 & 0.31 & 0.87 & 103.33 & 102.35 \\
\hline 6 & 0.67 & 0.43 & 0.8 & 0.64 & 0.46 & 102.98 & 106.97 \\
\hline 7 & 0.34 & 0.36 & 0.4 & 0.35 & 0.35 & 105.88 & 97.22 \\
\hline 8 & 0.39 & 0.14 & 0.19 & 0.38 & 0.15 & 97.43 & 107.14 \\
\hline 9 & 1 & 0.8 & 0.38 & 0.98 & 0.82 & 98.0 & 103.0 \\
\hline 10 & 0.64 & 0.66 & 0.38 & 0.65 & 0.65 & 101.56 & 98,48 \\
\hline 11 & 0.53 & 0.61 & 0.35 & 0.51 & 0.6 & 96.79 & 98.36 \\
\hline 12 & 1.06 & 0.23 & 0.16 & 1.1 & 0.22 & 103.77 & 99.13 \\
\hline 13 & 0.24 & 0.42 & 0.32 & 0.25 & 0.43 & 104.16 & 102.38 \\
\hline 14 & 1 & 0.59 & 0.74 & 0.97 & 0.56 & 97.5 & 96.44 \\
\hline 15 & 1.09 & 0.36 & 0.85 & 1.12 & 0.34 & 102.75 & 96.38 \\
\hline Mean recovery & & & & & & 102.40 & 100.72 \\
\hline $\mathrm{RSE}_{\text {single }} / \%$ & & & & & & 2.67 & 2.81 \\
\hline $\mathrm{RSE}_{\text {total }} / \%$ & & & & & & & \\
\hline
\end{tabular}

the first step of the algorithm (calculation of the variation matrix), so, the presence of such compounds does not perturb the data resolution. The proposed algorithm was used to the determination of $\mathrm{M}$ in the presence of two interferents ( $\mathrm{N}$ and $\mathrm{P})$. Quantification of $\mathrm{M}$ can be performed by plotting standard addition calibration curve, forth step of the proposed algorithm.

To check the ability of the proposed method, different simulated unknown mixtures were resolved by the proposed method and the results are shown in Table 1. The method succeeded in predicting the concentration of analyte in the presence of interferent.

\section{Experimental data set}

The experimental data sets are a series of kineticspectrophotometric two-way data of complexation reactions of $\mathrm{Co}(\mathrm{II}), \mathrm{Cu}(\mathrm{II})$ and $\mathrm{Ni}(\mathrm{II})$ with PAN in micellar media at $\mathrm{pH}$ 5.8. A number of synthetic ternary mixtures (Table 2) and several real samples were analyzed using the proposed method. These reactions follow a kinetic model, which is postulated in equation 11 :

$$
\begin{array}{ll}
\mathrm{Cu}+2 \mathrm{~L} \stackrel{k 1}{\longrightarrow} \mathrm{CuL}_{2} & \text { (a) } \\
\mathrm{Co}+2 \mathrm{~L} \stackrel{k 2}{\longrightarrow} \mathrm{CoL}_{2} & \text { (b) } \\
\mathrm{Ni}+2 \mathrm{~L} \stackrel{k 3}{\longrightarrow} \mathrm{NiL}_{2} & \text { (c) }
\end{array}
$$

Figure 3a shows the spectra of PAN and the complexes overlaping and therefore, each compound interferes in the spectrophotometric determination of the others. Figure 3 shows that the spectra and kinetic profiles of the complexation reactions of $\mathrm{Cu}(\mathrm{II}), \mathrm{Co}(\mathrm{II})$ and $\mathrm{Ni}$ (II) are different and could be used as a two-way data for their multicomponent analysis at unknown samples. In this case, $\mathrm{Cu}$ (II) was assumed as an interferent with constant signal that presents in real data. This assumption completely covers the presence of other constant interferents. In the proposed method, Beer's law was obeyed in the concentration range of 0.1-2.0 $\mu \mathrm{g} \mathrm{mL}^{-1}$ for $\mathrm{Co}(\mathrm{II})$ and $\mathrm{Ni}(\mathrm{II})$.

Preliminary studies of the experimental system (including the effect of $\mathrm{pH}$ and concentration of surfactant) was conducted by Afkhami and Bahram..$^{32}$ For this work, a citrate buffer solution of $\mathrm{pH} 5.8,1.4 \%$ (v/v) Triton X-100 and $1 \times 10^{-3} \mathrm{~mol} \mathrm{~L}^{-1} \mathrm{PAN}$ was applied. As mentioned before (see Figure 3), spectra and kinetic profiles of the complexation reactions of $\mathrm{Cu}$ (II), $\mathrm{Co}$ (II) and $\mathrm{Ni}$ (II) are different and could be used as two-way data to their multicomponent analysis at unknown samples. As can be seen in Figure 3, Cu(II) instantaneously reacts with PAN and produces a constant signal during experimental time. It was assigned as a constant interferent in order to more rigorously test the method. Its contribution and the contribution of other inert components are removed in the first step of proposed algorithm, in which the variation matrix is calculated. In order to establish the accuracy and precision of the method, several synthetic mixtures with different concentration ratios of $\mathrm{Cu}(\mathrm{II})$, $\mathrm{Co}(\mathrm{II})$ and $\mathrm{Ni}$ (II) were analyzed using the proposed method.

As mentioned before, the rank of a matrix based on reaction space is called the reaction rank. The reaction 
Table 2. A number of synthetic ternary mixtures of $\mathrm{Cu}(\mathrm{II}), \mathrm{Co}(\mathrm{II})$ and $\mathrm{Ni}(\mathrm{II})$ with $\mathrm{PAN}$ at micellar media and $\mathrm{pH} 5.8$ and the results for $\mathrm{Co}(\mathrm{II})$ and $\mathrm{Ni}(\mathrm{II})$ obtained by the proposed method

\begin{tabular}{|c|c|c|c|c|c|c|c|}
\hline \multirow{2}{*}{ Sample number } & \multicolumn{3}{|c|}{ Composition / $\left(\mu \mathrm{g} \mathrm{mL}^{-1}\right)$} & \multicolumn{2}{|c|}{ Predicted concentration / $\left(\mu \mathrm{g} \mathrm{mL} \mathrm{mL}^{-1}\right)$} & \multicolumn{2}{|c|}{ Recovery / \% } \\
\hline & $\mathrm{Ni}$ & Co & $\mathrm{Cu}$ & $\mathrm{Ni}$ & Co & $\mathrm{Ni}$ & Co \\
\hline 1 & 0.4 & 0.1 & 1.7 & 0.38 & 0.09 & 95.0 & 92.30 \\
\hline 2 & 1.0 & 0.8 & 0.2 & 1.02 & 0.77 & 102.0 & 96.25 \\
\hline 3 & 1.8 & 0.7 & 0.6 & 1.83 & 0.69 & 101.66 & 98.57 \\
\hline 4 & 0.3 & 1.6 & 0.7 & 0.27 & 1.45 & 90.0 & 90.62 \\
\hline 5 & 1.4 & 0.4 & 0.3 & 1.35 & 0.37 & 96.42 & 92.50 \\
\hline 6 & 0.2 & 1.6 & 0.4 & 0.22 & 1.42 & 110.0 & 88.75 \\
\hline 7 & 0.3 & 0.2 & 1.1 & 0.33 & 0.18 & 110.0 & 91.0 \\
\hline 8 & 0.4 & 1.5 & 0.6 & 0.39 & 1.52 & 97.50 & 101.33 \\
\hline 9 & 1.2 & 0.5 & 0.2 & 1.23 & 0.47 & 102.50 & 94.0 \\
\hline 10 & 0.2 & 0.9 & 0.5 & 0.23 & 0.88 & 115.0 & 97.77 \\
\hline 11 & 0.3 & 0.3 & 0.3 & 0.31 & 0.27 & 103.33 & 90 \\
\hline Mean recovery & & & & & & 102.12 & 93.91 \\
\hline $\mathrm{RSE}_{\text {single }} / \%$ & & & & & & 3.16 & 7.78 \\
\hline $\mathrm{RSE}_{\text {total }} / \%$ & & & & & & \multicolumn{2}{|c|}{6.11} \\
\hline
\end{tabular}
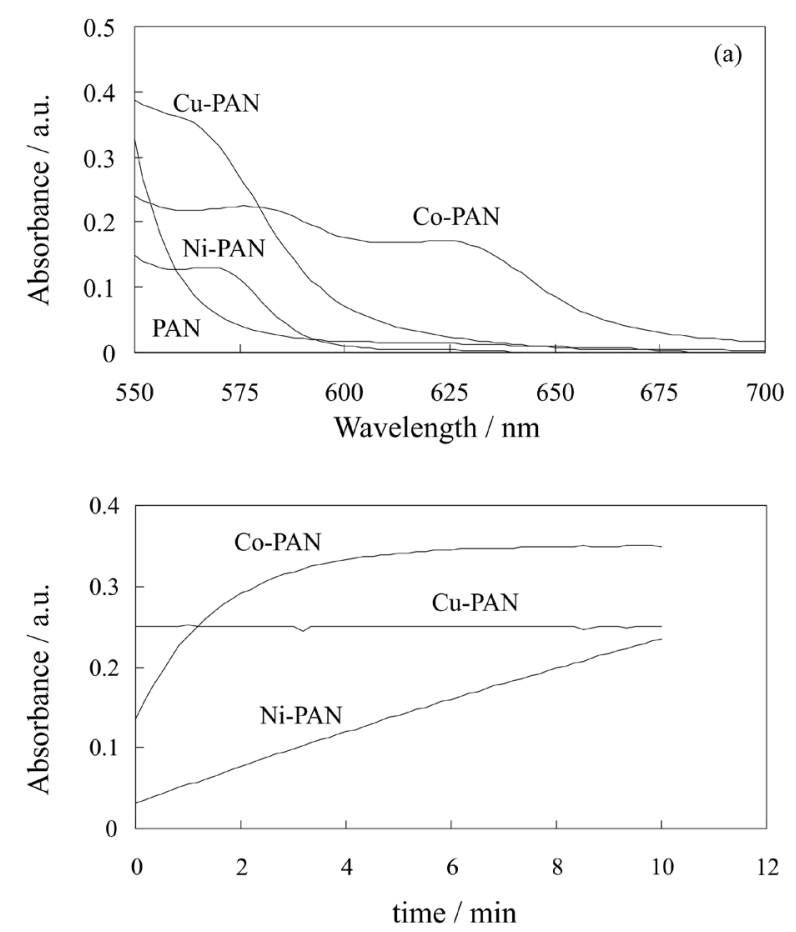

Figure 3. Spectra of complexed form of $\mathrm{Co}(\mathrm{II}), \mathrm{Cu}(\mathrm{II})$ and $\mathrm{Ni}(\mathrm{II})$ with PAN (a). The kinetic profiles of complexation reactions of $\mathrm{Co}$ (II), $\mathrm{Cu}$ (II) and $\mathrm{Ni}$ (II) with PAN (b) at micellar media, pH 5.8 and $25^{\circ} \mathrm{C}$.

rank of the augmented variation matrix of this system is two that is equal the number of active reactions in selected time range. But the raw data matrix is rank-deficient with the rank of three, because of the immediate complexation reaction of $\mathrm{Cu}(\mathrm{II})$ with $\mathrm{PAN}$, producing a constant signal during monitoring time. So, very complex and rankdeficient raw data matrix is converted to simple and full rank variation matrix based on the reaction rank using very simple pretreatment.
The iterative ALS procedure starts with initial estimation of the reaction spectra $\left(\mathbf{S}^{\mathrm{r}}\right)$. The reaction spectra of standard samples can be used as the first estimates. When all reaction spectra were estimated, it is then possible to obtain a first estimate of the extent reaction matrix $\mathbf{E}$ by least squares. The estimates of $\mathbf{E}$ and $\mathbf{S}$ are then refined by the ALS optimization. Non-negativity on extent reaction matrix was used as constraint in the ALS optimization. The proposed method can be easily extended to the systems with more components.

The prediction error of a single component in the mixtures was calculated as the relative standard error (RSE) of the prediction concentration using equation 12:32

$\operatorname{RSE}(\%)=\left(\frac{\sum_{\mathrm{j}=1}^{\mathrm{N}}\left(\mathrm{C}_{\mathrm{j}}-\mathrm{C}_{\mathrm{j}}\right)^{2}}{\sum_{\mathrm{J}=1}^{\mathrm{N}}\left(\mathrm{C}_{\mathrm{j}}\right)^{2}}\right)^{1 / 2} \times 100$

where $\mathrm{N}$ is the number of samples, $\mathrm{C}_{\mathrm{j}}$ is the concentration of the component in the $\mathrm{j}^{\text {th }}$ mixture and $\mathrm{C}_{\mathrm{j}}^{\wedge}$ is the estimated concentration. The total prediction error of $\mathrm{N}$ samples is calculated as equation 13 :

$\operatorname{RSE}_{\mathrm{t}}(\%)=\left(\frac{\sum_{\mathrm{i}=1}^{\mathrm{M}} \sum_{\mathrm{j}=1}^{\mathrm{N}}\left(\mathrm{C}_{\mathrm{ij}}-\mathrm{C}_{\mathrm{ij}}\right)^{2}}{\sum_{\mathrm{i}=1}^{\mathrm{M}} \sum_{\mathrm{J}=1}^{\mathrm{N}}\left(\mathrm{C}_{\mathrm{ij}}\right)^{2}}\right)^{1 / 2} \times 100$

where $\mathrm{C}_{\mathrm{ij}}$ is the concentration of the $\mathrm{i}^{\text {th }}$ component in the $\mathrm{j}^{\text {th }}$ samples and $\mathrm{C}_{\mathrm{ij}}^{\wedge}$ its estimate. Table 2 shows the single and total relative errors for such a system. Also the recovery and mean recovery are presented in there.

The study of the this example and also the simulation show how the strategy of application of variation matrix in 
conjunction with MCR-ALS was used in the determination of an analyte of interested in unknown samples and how the rank-deficiency problem in kinetic-spectrophotometric data was circumvented.

\section{Real samples}

The wider applicability of the proposed method was investigated. Two different synthetic alloy ${ }^{33-35}$ samples were analyzed for this purpose.

To remove the matrix effect in the determination of analytes, standards of them were added. Then, the reaction started by the addition of the reagent.

In complex multi species systems, it is hard to guess the involved number of reactions and species from inspection of the spectra. For this reason, the eigen analysis is used for estimating the number of reactions in the time range. Table 3 presents the eigen values and the ratios of consecutive eigen values of variation matrix for the above mentioned two real sample. The ratio of consecutive eigen values of variation matrix reaches maximum at $i=2$, therefore indicating that two reactions are taking place in considered systems.

Table 3. First four eigenvalues and ratios of consecutive eigenvalues of the variation matrix of samples

\begin{tabular}{cccccc}
\hline & \multicolumn{2}{c}{ Nillo alloy } & & \multicolumn{2}{c}{ Coal alloy } \\
\cline { 2 - 3 } \cline { 5 - 6 } & $\mathrm{g}_{\mathrm{i}}$ & $\mathrm{g}_{\mathrm{i}+1} / \mathrm{g}_{\mathrm{i}}$ & & $\mathrm{g}_{\mathrm{i}}$ & $\mathrm{g}_{\mathrm{i}+1} / \mathrm{g}_{\mathrm{i}}$ \\
\hline 1 & 19.645 & 34.913 & & 20.132 & 26.888 \\
2 & 0.562 & 58.171 & & 0.748 & 316.818 \\
3 & 0.009 & 8.061 & & 0.002 & 3.086 \\
4 & 0.001 & 9.072 & & 0.000 & 2.482 \\
\hline
\end{tabular}

Figure 4 shows the resolved reaction spectra and the reaction extent curves of real samples. Non-negativity on reaction extent was used as a constraint in ALS optimization. Concentration determination results of analytes in real sample are shown in Table 4. Spike method was used for checking the accuracy of results. Good recovery in Table 4 shows that the results are accurate.
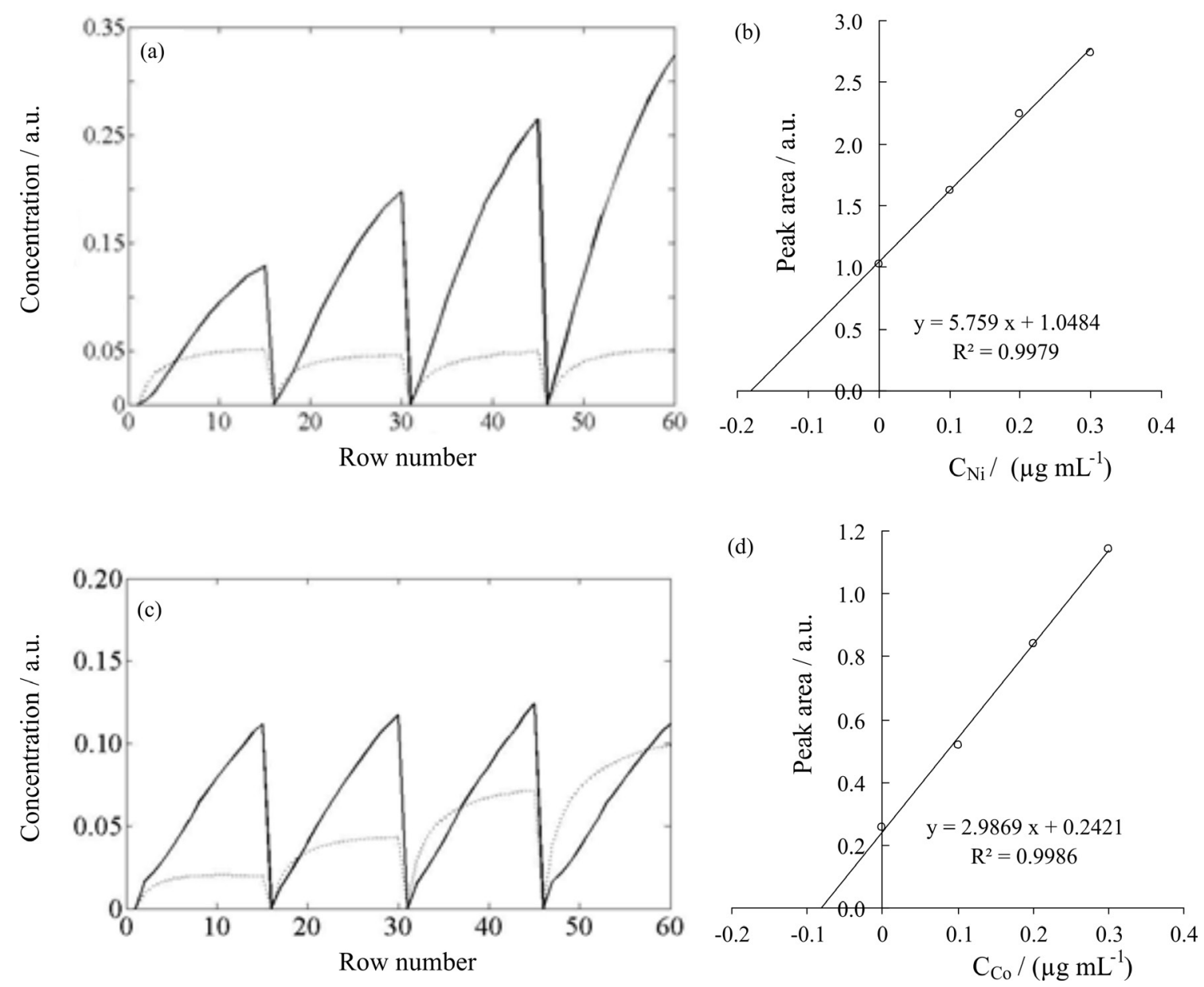

Figure 4. Resolved reaction extent curves for augmented variation matrix containing real and standard added sample for Ni (a) and its standard addition calibration curve (b), resolved reaction extent curves for augmented variation matrix containing real and standard added sample for Co (c) and its standard addition calibration curve (d). 
Table 4. Several synthetic alloy samples analyzed by proposed method

\begin{tabular}{|c|c|c|c|c|c|c|c|}
\hline \multirow{2}{*}{ Sample } & \multicolumn{3}{|c|}{ Composition / $\left(\mu \mathrm{g} \mathrm{mL}^{-1}\right)$} & \multicolumn{2}{|c|}{ Predicted concentration $^{\mathrm{a}} /\left(\mu \mathrm{g} \mathrm{mL}^{-1}\right)$} & \multicolumn{2}{|c|}{ Recovery / \% } \\
\hline & $\mathrm{Ni}$ & $\mathrm{Co}$ & $\mathrm{Cu}$ & $\mathrm{Ni}$ & $\mathrm{Co}$ & $\mathrm{Ni}$ & $\mathrm{Co}$ \\
\hline Coal alloy & 0.290 & 0.100 & 0.710 & 0.285 & 0.089 & 98.27 & 89.00 \\
\hline Nillo alloy & 0.295 & 0.170 & - & 0.288 & 0.180 & 97.62 & 105.88 \\
\hline
\end{tabular}

${ }^{a}$ The results are the average of three replicate measurements; ${ }^{b}$ composition of synthetic alloys: coal alloy is $\operatorname{Si}(7.8) \mathrm{Cu}(7.1) \mathrm{Mn}(2.0) \mathrm{Mg}(4.6) \mathrm{Cr}(2.7)$ $\mathrm{Ni}(2.9) \mathrm{Zn}(8.0) \mathrm{Sn}(2.0) \mathrm{Pb}(1.0) \mathrm{V}(1.5) \mathrm{Ga}(0.5) \mathrm{Co}(1.0) \mathrm{Sb}(0.10) \mathrm{Ca}(0.3) \mathrm{Ti}(1.5) \mathrm{Bi}(0.6) /\left(\mu \mathrm{g} \mathrm{mL}{ }^{-1}\right)$, and Nillo alloy $\mathrm{K}$ is $\mathrm{Ni}(29.5) \mathrm{Fe}(53) \mathrm{Co}(17) / \%$, prepared according to references 34 and 35.

The results demonstrate that the proposed algorithm succeeded in the determination of analyte in the presence of interferent(s) reaction (second-order advantage). In addition, the reaction spectrum of the interferent reaction can be extracted. Simultaneous determination of binary mixtures can be also successfully done using a variation matrix in the curve resolution procedure, the components equal to reaction numbers which are less than chemical components. Thus, the ambiguity is decreased in resolution step.

The proposed method can be used to analyze rank deficient data, in which inert component exists. This problem will occur when the reaction of one of the component immediately takes place, producing a constant signal during the time range of the experiments. As mentioned in previous work, ${ }^{25}$ rank annihilation factor analysis (RAFA) of such cases may be difficult and fails to give correct concentration of the analyte of interest. So, it is necessary to circumvent this problem. Also for applying multivariate curve resolution, the rank deficiency problem should be solved prior to analyzing. Several methods have been reported for this purpose and the applied method (variation matrix) is one of them. Our group has applied this preprocessing strategy prior to multivariate curve resolution to analyze rank-deficient complexometric data. In comparison with previous work, ${ }^{25}$ it should be noted that, RAFA was used to analyze gray systems but multivariate curve resolution (the proposed method) can be used to analyze the black systems, in which there is no information about interferent(s).

\section{Conclusions}

This work combines the advantages of variation matrix and standard addition method with those of MCR-ALS. A mathematical development was proposed for handling kinetic-spectrophotometric data in order to perform multicomponent analysis using variation matrix calculation. Using a variation matrix instead of original data matrix, the ambiguity is decreased in the resolution step because the components equal to reaction numbers which are less than chemical components. It was shown that the possible rank-deficiency problem was circumvented using variation matrix concept. All the theoretical development and strategies of analysis were shown to be particularly useful to understand the analysis and the obtained results on real problems involving different alloy samples.

\section{References}

1. Smilde, A. K.; Tauler, R.; Saurina, J.; Bro, R.; Anal. Chim. Acta 1999, 398, 237.

2. Escandar, G. M.; Olivieri, A. C.; Faber, N. M.; Goicoechea, H. C.; de la Pena, A. M.; Poppi, R. J.; TrAC, Trends in Anal. Chem. 2007, 26, 752.

3. Wold, S.; Sjostrom, M.; Eriksson, L.; Chemom. Intell. Lab. Syst. 2001, 58, 109.

4. Garcia-Reiriz, A.; Damiani, P. C.; Olivieri, A. C.; Chemom. Intell. Lab. Syst. 2010, 100, 127.

5. Abdollahi, H.; Soruraddin, M. H.; Naseri, A.; Anal. Sci. 2006, $22,263$.

6. Ni, Y.; Huang, C.; Kokot, S.; Anal. Chim. Acta 2007, 599, 209.

7. Culzoni, M. J.; Goicoechea, H. C.; Ibanez, G. A.; Lozano, V. A.; Marsili, N. R.; Olivieri, A. C.; Pagani, A. P.; Anal. Chim. Acta 2008, 614, 46.

8. Saurina, J.; Hernandez-Cassou, S.; Tauler, R.; Izquierdo-Ridorsa, A.; Anal. Chem. 1999, 71, 126.

9. Bro, R.; Chemom. Intell. Lab. Syst. 1997, 38, 149.

10. Sanchez, E.; Kowalski, B. R.; Anal. Chem. 1986, 58, 496.

11. Ho, C. N.; Christian, G. D.; Davidson, E. R.; Anal. Chem. 1980, 52, 1071 .

12. Bahram, M.; Mabhooti, M.; Anal. Chim. Acta 2009, 639, 19.

13. Sanchez, E.; Kowalski, B. R.; J. Chemom. 1990, 1, 29.

14. Linder, M.; Sundberg, R.; J. Chemom. 2002, 16, 12.

15. Wu, H. L.; Shibukawa, M.; Oguma, K.; J. Chemom. 1998, 12, 1.

16. Chen, Z. P.; Wu, H. L.; Jiang, J. H.; Li, Y.; Yu, R. Q.; Chemom. Intell. Lab. Syst. 2000, 52, 75.

17. Hu, L. Q.; Wu, H. L.; Ding, Y. J.; Fang, D. M.; Xia, A. L.; Yu, R. Q.; Chemom. Intell. Lab. Syst. 2006, 82, 145.

18. De Juan, A.; Casassas, E.; Tauler, R. In Encyclopedia of Analytical Chemistry, vol. 11, Myers, R. A., ed.; Wiley: Chichester, U. K., 2002, p. 9800-9837. 
19. Saurina, J.; Hernandez-Cassou, S.; Tauler, R.; Anal. Chem. 1997, 69, 2329.

20. Saurina, J.; Hernandez-Cassou, S.; Tauler, R.; Izquierdo-Ridorsa, A.; J. Chemom. 1998, 12, 183.

21. Amrhein, M.; Srinivasan, B.; Bonvin, D.; Schumacher, M. M.; Chemom. Intell Lab. Syst. 1996, 33, 17.

22. Jiang, J.; Sasic, S.; Yu, R.; Ozaki, Y.; J. Chemom. 2003, 17, 186.

23. Jiang, J.; Ozaki, Y.; Kleimann, M.; Siesler, H. W.; Chemom. Intell. Lab. Syst. 2004, 70, 83.

24. Abdollahi, H.; Sajjady, S. M.; J. Chemom. 2009, 23, 139.

25. Bahram, M.; Mabhooti, M.; J. Chemom. 2009, 23, 236.

26. Naseri, A.; Abdollahi, H.; Anal. Methods 2011, 3, 429.

27. Gomez, V.; Cuadros, R.; Ruisanchez, I.; Callao, M. P.; Anal. Chim. Acta 2007, 600, 233.
28. Lozano, V. A.; Ibanez, G. A.; Olivieri, A. C.; Anal. Chim. Acta 2009, 651, 165.

29. Samari, F.; Hemmateenejad, B.; Shamsipur, M.; Anal. Chim. Acta 2010, 667, 49.

30. Saurina, J.; Tauler, R.; Analyst 2000, 125, 2038.

31. Xu, C. J.; Gourvenec, S.; Liang, Y. Z.; Massart, D. L.; Chemom. Intell. Lab. Syst. 2006, 81, 3.

32. Afkhami, A.; Bahram, M.; Anal. Chim. Acta 2004, 526, 211.

33. Abdollahi, H.; Anal. Chim. Acta 2001, 442, 327.

34. Macit, M.; Bati, H.; Bati, B.; Turk. J. Chem. 2000, 24, 81.

35. Davis, J. R. In Metals Handbook: Corrosion, vol. 16, $9^{\text {th }}$ ed.; ASM International: Materials Park, Ohio, 1989, p. 836.

Submitted: January 11, 2011

Published online: October 6, 2011 